\title{
O ORGASMO É INFLUENCIADO PELA TRH? O USO DE TIBOLONA
}

\author{
Henry George!
}

0 orgasmo pertence ao grupo das emoções agradáveis, ultimando a fase de excitação sexual e reunindo alterações fisiológicas e anatômicas, como rubor facial, taquicardia, taquisfigmia, contraturas musculares, lubrificação vaginal, miotonia da musculatura do intróito vaginal ritmicamente (plataforma orgástica); pode ser de muitas formas inibido por fatores culturais, educacionais ou religiosos, de forma que muitas mulheres (cerca de 30\%) nunca o experienciaram, o que chamamos de anorgasmia primária, mas há aquelas que deixaram de senti-lo após algum fato marcante em suas vidas (anorgasmia secundária), tais como desajustes conjugais, culpas, repressões, oorofectomias e climatério.

A fim de restabelecer o bem-estar geral destas pacientes e, ao mesmo tempo, fazermos uma prevenção do infarto agudo do miocárdio, osteoporose, mal de Alzheimer, distúrbios urogenitais e melhorarmos a função sexual e a libido destas pacientes, introduzimos a terapia de reposição hormonal, que deve ser preferencialmente feita com estrogênio, que é um hormônio já produzido normalmente pelo ovário, mas na impossibilidade disso, devido aos efeitos deletérios do estrogênio sobre as mamas e o endométrio, podemos e devemos lançar mão da tibolona, produto sintético de uso exclusivo oral e que tem uma ação estrogênica, progestogênica e androgênica fracas, mas que, segundo estudos

\footnotetext{
'Médico; mestrando em Sexologia da UGF/RJ. E-mail: henry@compuland.com.br
} 
comprovados, melhoram muito a libido e a função sexual dessas pacientes, fazendo ao mesmo tempo uma cardioproteção e mantendo o perfil lipídico, a massa muscular, a cognição e a disposição para uma vida mais longa e com qualidade. 